DOI 10.37882/2500-3682.2020.06.10

\title{
ТЕОРЕТИЧЕСКИЙ ОБЗОР РЕФЛЕКСИВНОСТИ В КОНТЕКСТЕ ИНДИВИДУАЛЬНОГО СТИЛЯ УЧЕБНОЙ ДЕЯТЕЛЬНОСТИ
}

\section{THEORETICAL REVIEW ON REFLECTIVITY IN THE CONTEXT OF THE INDIVIDUAL STYLE OF EDUCATIONAL ACTIVITY}

\section{Maksimova}

Summary: The article considers the basic approaches to the study of the individual style of educational activity and reflexivity. Theoretical foundations of research in the field of psychophysiological components of a successful activity and the importance of reflexivity in the process of human interaction with the environment.

Keywords: reflexivity, individual style of educational activity, Kolb D., Learning Styles Inventory, A.V. Karpov, situational reflection.

\author{
Максимова Мария Васильевна \\ аспирант, Башкирский государственный университет \\ Maksimova8531@gmail.com
}

Аннотация: В статье рассмотрены базовые подходы к изучению индивидуального стиля учебной деятельности и рефлексивности. Даны теоретические основы исследований отечественных и зарубежных учёных на предмет психофизиологических компонентов успешной деятельности и значимости рефлексивности в процессе взаимодействия индивидуума с окружающей средой.

Ключевые слова: рефлексивность, индивидуальный стиль учебной деятельности, Перечень стилей обучения Д. Колба, А.В. Карпов, ситуативная рефлексия.

В зарубежной психологии понятие стилевых свойств личности, когнитивного стиля или реактивного стиля вытекает из противопоставления формально-динамических свойств содержательным. Реактивный стиль, в свою очередь, (как например, импульсивность или рефлексивность) является одним из существенных проявлений темперамента.

На сегодняшний день наибольшую популярность имеет теория модели обучения, основанного на опыте, Дэвида Колба, которым также был разработан опросник «Перечень стилей обучения - ПСО» (с англ. «Learning Styles Inventory», LSI) для оценки индивидуальных стилей обучения. Концепция Колба отражает влияние Пиаже (исследования развития), Дьюи (обучение на основе опыта), Левина (диалектическое напряжение между аналитическим мышлением и конкретным опытом), Юнга (идеи типов и непредпочтительных форм обучения). Модель опытного обучения (МOO) предполагает, что человек обучается путём прямого познания мира, отражения своего собственного опыта, составления представлений и абстрактного мышления о мире и активного участия в нем. Обучение, по Колбу, - это процесс, посредством которого знание создаётся через преобразование опыта. Данный процесс опосредован четырьмя компонентами, включая следующие: (1) аффективный (ощущения, чувства), (2) символический (познание, навыки размышления), (3) поведенческий (свершения) и (4) перцепционный (восприятие, навыки наблюдения). Постулируя эволюционную теорию обучения, Колб предусматривает эти четыре компонента как основания конуса, где четыре компонента создают вершину по мере того, как индивид развивается, а стиль обучения становится более сложным. 
Колб определяет четыре способа обучения, которые соответствуют данным компонентам. Их понимают как способности к обучению и определяют следующим образом: (1) конкретный опыт (КО) - чувства, (2) рефлексивное наблюдение (РН) - рефлексия, (3) абстрактная концептуализация (АК) - абстракция, размышление, (4) активное экспериментирование (АЭ) - действие, выполнение. Согласно модели, обучающиеся должны решить диалектическое напряжение между непосредственным конкретным опытом и аналитической отрешённостью. В модели Колба существуют два учебных континуума. Обучающиеся должны выбрать положение между АК и КО в одном континууме и между АЭ и $\mathrm{PH}$ - в другом. Эти два учебных континуума или учебные компоненты являются полярными друг к другу (т.е. формируют биполярные континуумы). Сочетание выборов, сделанных одним человеком между способностями, показывают, как превалирование одной способности над другой, так и предпочтение особого конструкта или сочетания способностей, а именно, стиля обучения.

Стиль обучения, в свою очередь, заключается, по Колбу, в том, как человек обходится с идеями и каждодневными ситуациями. Он утверждает, что обучение это процесс развития, который происходит по часовой стрелке циклически от КО к РН, АК, АЭ и обратно к КО, откуда процесс продолжается по кругу. Диалектическая напряжённость между полярными способностями требует от обучающегося постоянного решения конфликтов между способностями и интеграции их в более сложные навыки. Со временем обучающиеся развивают предпочтение либо к АК (абстрактность) и КО (конкретность), либо к АЭ (действие) и РН (рефлексия). Специфическая комбинация данных предпочтений раскрывает четыре стиля обучения: дивергеры, ассимиляторы, конвергеры и аккомодаторы. Каждый стиль обучения имеет характерные формы отношения к идеям и каждодневным ситуациям. Дивергеры заинтересованы в людях, генерируют идеи и имеют склонности к богатому воображению. Дивергеры предпочитают рефлективное наблюдение (РН) активному экспериментированию (АЭ) и конкретный опыт (KO) абстрактной концептуализации (АК). Конвергеры, напротив, отдают предпочтение скорее вещам, чем людям, относительно неэмоциональны и хорошо проявляют себя в логических умозаключениях. Конвергеры - индивиды, делающие выбор в пользу АК над КО и в пользу АЭ над РН. Зато у ассимиляторов доминируют рефлективное наблюдение (РН) и абстрактная концептуализация (АК). Такие люди прекрасно проявляют индуктивное мышление и хорошо усваивают информацию, они менее заинтересованы в людях, чем в вещах, и склоняются к логике, нежели к точности правильности и прилежании. И наконец, аккомодаторы выбирают конкретный опыт (АК) и активное экспериментирование (АЭ). Такие индивиды легко сходятся с людьми и наслаждаются новыми ощущениями. Считается, что они те, кто берут на себя риск и решение проблем. Если на этапе критической рефлексии человек рассматривает новый опыт с точки зрения предшествующего опыта, то на этапе абстрактной концептуализации он, используя логику, пытается искать ответы: формирует гипотезы, делает обобщения и выводы. [4]

В этой связи особый интерес представляет рефлексивность как универсальное и системообразующее качество психики, способствующее успешному усвоению, расширению и преобразованию социального опыта.

\section{Основная часть исследования}

В западной психологии к вопросам рефлексии обращались Дж. Холмс, Ч. Кули, Т. Ньюком, чьи эксперименты проводились для изучения диад - парных субъектов, задействованных в каком-либо общем процессе в условиях лабораторного эксперимента. Джон Холмс стремился определить степень влияния социума на способность к рефлексии. Он описал три составляющих «Я», где «Я - реальное» - то, что мы представляем собой на самом деле; «Я - идеальное» - идеализированный образ человека, нарисованный им самим. И третий вид - это «Я», каким человека воспринимает его окружение. Приверженцам теории Холмса такое растроение личности показалось недостаточным, и они предложили добавить еще одно «я»: наше представление о том, как именно мы выглядим в чужих глазах. Рефлексия напоминает комнату с зеркалами, где один образ человека отражается несколько раз. Чаще всего отражение, увы, оказывается искаженным. [2]

Философ и педагог Джон Дьюи в своих работах приводил доводы к положениям рефлексивного обучения. Рефлексия, по его мнению, характеризуется двойственным положением, представляющим дилемму. Потребность в разрешении сомнения является постоянным и руководящим фактором во всём процессе рефлексии. Где нет вопроса, или проблемы для разрешения, или где нет затруднения, которое нужно преодолеть, поток мыслей идет наобум. Проблема устанавливает цель мысли, а цель контролирует процесс мышления. [3]

Дж. Дьюи рассматривает цельный акт рефлективного мышления с выделением пяти частных логических ступеней, первым среди которых выступает чувство затруднения. За этим следует исследование его границ, и выявление вероятного решения. После происходит развитие за счёт выявления способов действия. Ну, и в заключение, дальнейшие наблюдения, с целью выработки новых алгоритмов действия.

Среди отечественных учёных вопрос рефлексии поднимали С.Л. Рубинштейн, Г.П. Щедровицкий, А.А. Бодалёв, В.В. Знаков, Д.А. Леонтьев, Г.М. Андреева, А.В. Россохин, 
А.М. Матюшкин, А.С. Шаров, В.А. Петровский, М.С. Егорова, И.Н. Семёнов, С.Ю. Степанов и многие другие. Г.П. Щедровицкий рассматривает рефлексивность в качестве базового свойства личности, которое делает возможным осознание и регуляцию собственной деятельности субъектом рефлексии. М.С. Егорова отмечает большое значение рефлексивности в процессе формирования межличностных взаимодействий и индивидуальных стилей деятельности. [13]

Большой вклад в исследование проблемы рефлексивности сделал ярославский психолог А.В. Карпов. В своих работах он рассматривает рефлексивность как психическое свойство особой природы, имеющее направленность (интра-, интерпсихическая рефлексия), а также классифицирует рефлексивность на три вида по «временному» принципу: ситуативную (актуальную), ретроспективную и перспективную рефлексию. [6]

Отечественные исследователи, в частности Г.М. Андреева, указывает на необходимость изучения рефлексии не на диаде, но на более крупных реально существующих общностях людей, связанных коллективной деятельностью, для оптимального изучения явления.

В последней трети XX в. учёные отходят от использования рефлексии как одного из принципов, объясняющих функционирование психических процессов, и начинают выделять рефлексию уже как особый предмет изучения.

С.Л. Рубинштейн дополняет понятие рефлексии аксиологическим аспектом. Он выделил два преимущественных способа человеческого существования: это 1) жизнь, которая не выходит за пределы непосредственных отношений человека (что представляет собой естественный процесс с очевидными целостностью и непосредственностью человека); и 2) способ рефлексии, позволяющей прервать процесс жизни и как бы выйти за его пределы. Что самом по себе без сомнения является поворотным моментом для индивида. Здесь начинается либо путь к душевной опустошенности, к нигилизму, к нравственному аскетизму, к цинизму, к моральному разложению (или в менее острых случаях к моральной неустойчивости), или другой путь - к построению нравственной человеческой жизни на новой, сознательной основе. С появлением рефлексии связано философское осмысление жизни. [10]

Рефлексия представляется комплексным, многогранным, процессом, через который субъект может получить знания о самом себе, а также о том, каким он видится другому индивиду. Рефлексия, таким образом, - это процесс удвоенного, зеркального взаимоотображения субъектами друг друга, содержанием которого выступает воспроизведение, воссоздание особенностей друг друга. [12]
Множество талантливых отечественных учёных занимались исследованием и разработкой проблемы рефлексии.

И.Н. Семёнов и С.Ю. Степанов выделяют 4 подхода (или же аспекта) изучения рефлексии.

1. Кооперативный (А.В. Карпов, Г.П. Щедровицкий, В.А. Лефевр). Применяется при рассмотрении анализируемых видов деятельности типа субъектсубъект, а кроме этого и при планировании коллективной деятельности с условием определения внутригрупповых ролей субъектов и их профессиональных позиций.

2. Коммуникативный / социально-психологический (А.А. Бодалёв, Г.М. Андреева). Здесь рассмотрение рефлексии ведётся как уже неотъемлемого элемента высокоразвитого общества и восприятия личностями друг друга, как особой черты познавательной способности человека человеком.

3. Когнитивный / интеллектуальный (А.В. Брушлинский, И.Н. Семёнов, А.М. Матюшкин). Исследователи, придерживающиеся этого подхода, рассматривают рефлексию как способность субъекта выявлять, проводить анализ и соотносить с предметной ситуацией свои поступки. Помимо этого, учёные разрабатывают проблему связи рефлексии с механизмами мышления (в особенности теоретического).

4. Личностный / общепсихологический (Д.А. Леонтьев, В.В. Знаков, Н.И. Гуткина, В.А. Петровский, И.Н. Семёнов, С.Ю. Степанов, А.С. Шаров). Приверженцы этого подхода делают упор на построение новых образов себя через коммуникацию с окружением и активную деятельность. Кроме прочего, вырабатываются новые знания о мире.

Рефлексия раскрывается как особая функция, обеспечивающая осознанное планирование и регулирование собственных действий, а также мыслительных операций.

В исследованиях С.Ю. Степанова и И.Н. Семенова даётся концепция двух видов рефлексии: кооперативная и коммуникативная. В контексте индивидуального стиля учебной деятельности для нас имеет большее значение первая, так как именно за счёт нее происходит структурирование и координирование совместный действий в коллективе. При этом рефлексия рассматривается как «высвобождение» субъекта из процесса деятельности, его «выход» во внешнюю, новую позицию как по отношению к прежним, уже выполненным действиям, так и по отношению к будущей, проектируемой деятельности с целью обеспечения взаимопонимании и согласованности действий в условиях совместной деятельности. [11]

Такое направление как личностная рефлексия опре- 
деляет восприятие человеком собственных поступков, а также образ «Я» как индивидуальности. Можно выделить три этапа протекания личностной рефлексии: 1) переживание ситуации или задачи как неразрешимой; 2) тестирование стереотипов действий и отказ от тех, что не прошли проверку; 3) переоценка стереотипа, наряду с проблемной ситуацией и своего места в ней. Процесс переосмысления выражается, во-первых, в изменении отношения субъекта к самому себе, к собственному «Я» и реализуется в виде соответствующих поступков, а, вовторых, в изменении отношения субъекта к своим знаниям и умениям. При этом переживание конфликтности не подавляется, а обостряется и ведёт к мобилизации ресурсов «Я» для достижения поставленной цели. [1]

Отечественный учёный Ю.М. Орлов считает, что личностный тип рефлексии несет функцию самоопределения. Он утверждает, что личностный рост возможен только тогда, когда индивид переживает осознание смысла. А процесс самопознания, в виде постижения своей Я-концепции, включающей воспроизведение и осмысление того, что мы делаем, почему делаем, как делаем и как относились к другим, и как они относились к нам и почему, посредством рефлексии ведет к обоснованию личностного права на изменение заданной модели поведения, деятельности, с учетом особенностей ситуации. [8]

Кроме указанных аспектов можно выделить также экзистенциальную (где объектом выступают глубинные смыслы личности), культуральную и саногенную рефлексии. Последняя возникает как результат переживания глубоких негативных эмоций (таких как вина, гнев, обида, стыд и т.д.) Её основная функция - контроль и регуляция эмоциональных состояний человека.

Н.И. Гуткина выделяет следующие виды рефлексии: 1). Логическая - рефлексия в области мышления, предметом которой является содержание деятельности индивида. 2). Личностная - рефлексия в области аффективнопотребностной сферы, связана с процессами развития самосознания. 3). Межличностная - рефлексия по отношению к другому человеку, направлена на исследование межличностной коммуникации. [1]

Е.В. Лушпаева описывает следующий тип - «рефлексия в общении», который представляет собой сложную систему рефлексивных отношений, возникающих и развивающихся в процессе межличностного взаимодействия. Она выделяет следующие компоненты в структуре данного типа: личностно-коммуникативная рефлексия (рефлексия «Я»); социально-перцептивная (рефлексия другого «Я»); рефлексия ситуации или рефлексия взаимодействия. [7]

В исследованиях А.В. Карпова рефлексия предста- ёт как особая синтетическая психическая реальность, дифференцированная по классической триаде на психические процессы, психические свойства и психические состояния. При этом она не сводиться единственно ни к одному из них.

Рефлексия - это одновременно и уникальное свойство, присущее лишь человеку, и состояние осознания чего-либо, и процесс репрезентации психике своего собственного содержания. Именно такое понимание, позволяя дифференцировать основные модусы рефлексии и тем самым конкретизировать предмет психологии рефлексии, обеспечивает и сохранение того единства, в котором в психике представлены процессы, свойства и состояния. [6]

Для нашего исследования представляет интерес категория «психическое свойство», т.е. рефлексивность как качественно новое свойство индивида.

Опираясь в своей классификации на «временной принцип», А.В. Карпов определяет ситуативную (актуальную), ретроспективную и перспективную рефлексии.

Ситуативная рефлексия заключается в самоконтроле человеком своего поведения в какой-либо актуальной ситуации, а также осознании и анализе происходящего с последующей координацией дальнейших действий с учётом изменения ситуации.

Поведенческими проявлениями и характеристиками этого вида рефлексии являются, в частности, время обдумывания субъектом своей текущей деятельности; то, насколько часто он прибегает к анализу происходящего; степень развернутости процессов принятия решения; склонность к самоанализу в конкретных жизненных ситуациях. [5]

Ретроспективная рефлексия характеризуется склонностью к постоянному прокручиванию информации, имевшей место в прошлом, анализу собственных действий и произошедших событий. Предметами рефлексии здесь становятся ошибки личности, итоги деятельности и причины и следствия случившегося. Этот вид рефлексии проявляется в длительности и частоте переживаний по поводу того, что случилось или не случилось.

Перспективная рефлексия представляет собой анализ будущей деятельности и собственного поведения в моделируемой ситуации. Тщательное планирование и детальное прогнозирование являются неотъемлемой частью этого вида рефлексии. А также стоит отметить ориентацию на будущее как характерную черту данного типа.

Кроме прочего, в соответствии с критерием направ- 
ленности А.В. Карпов производит деление рефлексии на «интра- и интерпсихическую».

Первая соотноситься с рефлексивностью как способностью к самовосприятию содержания своей собственной психики и его анализу, вторая со способностью к пониманию психики других людей, включающей наряду с рефлексивностью как способностью «встать на место другого» также и механизмы проекции, идентификации, эмпатии. [5]

Отсюда следует, что общее свойство рефлексивности вбирает в себя оба выделенных типа, при том, что уровень развития этого свойства представляет собой производное от них обоих одновременно.

Помимо прочего А.В. Карпов выделяет уровни рефлексии исходя из степени сложности рефлектируемого содержания. На первом уровне происходит разноплановая оценка человеком собственных чувств (относитель- но конкретной ситуации) и поведения других людей. На втором уровне субъект производит суждение о чувственном опыте другого человека, оказавшегося в похожей ситуации. Третий уровень подразумевает моделирование субъектом представления о восприятии своего мнения другим человеком. И четвертый, заключительный, уровень отражает восприятие субъектом мнения другого человека о своем поведении.

\section{Выводы}

Рефлексивность является универсальным и системообразующим качеством личности, которое делает возможным успешное освоение, расширение и преобразование социального опыта. В рассмотрении способности индивида к рефлексии в контексте индивидуального стиля учебной деятельности заложен объяснительный и развивающий потенциал, что в свою очередь может стать стартовой базой для повышения эффективности обучения.

\section{ЛИТЕРАТУРА}

1. Гуткина Н.И. Личностная рефлексия в подростковом возрасте: Дис. на соиск. уч. степени канд. психол. наук / Академия педагогических наук СССР. — М., 1983. - $176 \mathrm{c}$.

2. Данилин К.Е. Диада или триада. Рига. 1974. - 76 с.

3. Дьюи, Дж. Психология и педагогика мышления. - М., 1999. - 192 с. 14с., с.60.]

4. Ишков А.Д. Учебная деятельность студента: психологические факторы успешности: Монография. - М.: Издательство АСВ. - 224 стр., 2004

5. Карпов А.В. Психология рефлексивных механизмов деятельности. - М.: Изд-во «Институт психологии РАН», 2004. - 424с.

6. Карпов А.В. Рефлексивность как психическое свойство и методика ее диагностики// Психологический журнал. 2003. Т. 24. № 5. С. 45-57.

7. Лушпаева Е.В. Развитие рефлексии в общении средствами социально-психологического тренинга. Дис. на соиск. уч. степени канд. психол. наук M., 1989.]

8. Орлов Ю.М. Самопознание и самовоспитание характера. М.: Просвещение, 1987. -224 с.

9. Психология индивидуальных различий. / Под ред. Ю.Б. Гиппенрейтер, В.Я. Романова. М., 2000. С. 128-139

10. Рубинштейн С.Л. Проблемы общей психологии. - М., 1973. - С. 351, 352. 320

11. Семенов И.Н., Степанов С.Ю. Рефлексивная психология и педагогика творческого мышления. Запорожье. 3 Гу. 1992

12. Словарь практического психолога. - М.: АСТ, Харвест. С.Ю. Головин. 1998.

13. Щедровицкий Г.П. Рефлексия и ее проблемы. - М., 1975.

( Максимова Мария Васильевна (Maksimova8531@gmail.com).

Журнал «Современная наука: актуальные проблемы теории и практики» 